\title{
Las relaciones históricas como precedentes del periodismo granadino
}

\author{
Dr. Javier González Antón
}

Prof. Titular de Documentación Periodística, Universidad de La Laguna

\begin{abstract}
RESUMEN
Las relaciones históricas son impresos informativos, antecedentes inmediatos de las primeras gacetas y de todo el periodismo. A partir de más de 150 editadas en Granada durante los siglos XVI a XVIII se estudian desde todos los aspectos, su presentación como pliegos sueltos, formato, páginas, tipos e ilustraciones. Sus autores e impresores, así como los contenidos, los principales temas, desde los bélicos, pasando por los políticos y sociales, hasta los festivos y de sucesos. La descripción de la realidad y de los hechos de actualidad, el sensacionalismo, la truculencia y el moralismo de las relacionadas con descripciones de hechos extraordinarios, así como su escaso precio, abonan su carácter popular, su importancia dentro de la publicística, y refuerzan su estrecha relación con la prensa.
\end{abstract}

\begin{abstract}
The "relaciones" are informative documents, antecedents of the first gacettes and the whole journalism. Fron more than 150 edited in Granada since the XVI century to the XVIII century we can studie all their aspects. Their presentation as odd sheets, the format, pages, kinds and pictures. Their authors and printers, the contents and the main subjects. (From belic and politic to festive and events). The description of the reality and the actuality events, the sensacionalism, cruelty and the moralism and his lower prices improve their popular character and their importance in the journalism.
\end{abstract}

Palabras claves: Relaciones históricas/Publicística/Antecedentes del periodismo/Pliegos sueltos/ Granada/Información de actualidad.

Key Words: Relaciones/Antecedents of journalism/Odd sheets/Granada/Information.

\section{Introducción}

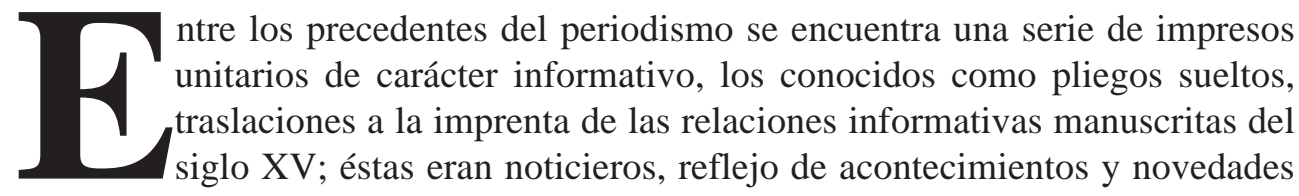


locales que aparecían ocasionalmente (1) Ello responde a las necesidades de información del pueblo, ávido de narraciones de acontecimientos bélicos, políticos o insólitos, a lo que no es ajeno la polémica.

En la sociedad estamental de los siglos XVII y XVIII, la publicística desempeñaba un papel semejante al del periodismo de los siglos posteriores (2), los impresos, como las relaciones, manifiestos, etc. cubrían las mismas necesidades, por su valor informativo, polémico y cultural.

Como señala Bellanger (3), la relación o "nouvelle" impresa sucede a fines del XV a la manuscrita. Ella ofrece ya características propias de la prensa: trata de la actualidad, informa, busca el sensacionalismo, sólo queda a falta de la periodicidad, ya que son lanzadas ocasionalmente con motivo de acontecimientos reales o imaginarios.

La conexión entre las "relaciones" y el periodismo ha sido siempre estrecha, hasta el punto de que el primer número de la gazeta madrileña se titulaba Relación o Gazeta de algunos casos..., o, como algún investigador metafóricamente señala, las "relaciones desembocan en las gacetas como los afluentes en los ríos".

Tampoco se habían definido las diferencias y límites entre cualesquiera de los impresos no unitarios, ya fueran folletos, obras completas de publicación fraccionada o periódicos.

Las gacetas enlazan con el "relacionismo" de los descubrimientos, de las conquistas, de las empresas exteriores y de las fiestas sacras y populares. Según Gómez Aparicio (4) lo que hace la gaceta es "sistematizar la información, abrir un cauce de satisfacción de la necesidad, más viva cada día, de noticias transparentes y escuetas..."

Hasta entonces, la opinión pública se ha transmitido, pues, a través de las relaciones, cartas o «nouvelles á la main». Como ya hemos señalado (5), la gran importancia política de España, y su intervención en múltiples acontecimientos internacionales como guerras y descubrimientos, hace que nuestro país, en este periodo de la información, sea el más destacado tanto en número como por la difusión y variedad de las relaciones. También Kástner (6) considera que para todo lo que sucedía en Europa los periódicos españoles eran de los de más importancia, porque estas noticias llegaban en barcos españoles y "desde ésta se esparcían por

1 Altabella, José, “Las Provincias”. Eje histórico del periodismo valenciano. 1866-1969. Madrid, 1970, pág. 22.

2 Pérez Picazo, María Teresa, La publicística española en la Guerra de Sucesión. Madrid, 2 vols. 1, pág. 18.

3. Bellanger (et al.), Histoire générale de la presse française. París, 1969, pág. 29.

4. Gómez Aparicio, Historia del periodismo español. Madrid, 1967, 1, pág. 33.

5 González Antón, Javier, Pliegos sueltos y periódicos granadinos. Memoria de licenciatura. Universidad de Granada. 1981. págs. 75-80.

6 Alfred Kástner, Historia de la prensa española. Tesis, Leipzig, 1926, pág. 16. 
todo el país y los estados vecinos». No es casualidad que nombres españoles de imprenta hayan sido empleados en el extranjero, y esto demuestra la gran importancia de la prensa española de aquellos tiempos, caso del empleo de la palabra «copia», en vez de «Abschrift" que se encuentra en los encabezamientos alemanes de entonces.

Pero, desafortunadamente, gran parte de esos impresos se han perdido, como señala Blasco (7). Las causas eran diversas: la escasa tirada, su carácter de hoja volante no encuadernada, la naturaleza efímera de lo narrado, etc.

De esa gran difusión de impresos son consumidores preferentes los habitantes de las ciudades, sobre todo de aquellas frecuentes focos de información, caso de puertos como Sevilla y también Granada. Aguilar Piñal (8) ha resaltado el importante papel de las imprentas andaluzas, como Sevilla, Málaga, Cádiz, y Granada, con Madrid y Valencia, así como la preponderancia de los temas y autores de la región andaluza.

Para Kástner, el acontecimiento más difundido de la época sería la Guerra de Granada, ya del año 1487 se conoce un Informe sobre la reconquista de Málaga, con el discurso hecho por los cardenales sobre el acontecimiento. Muchas de las noticias sobre Granada se tradujeron a diversos idiomas, como la de In Laudem.. o La trés celebre... (9). Con ello prácticamente se inaugura una nueva etapa en la comunicación de la información, la relación impresa. Granada, como tema usual, entra igualmente en el proceso informativo moderno que desembocará en la prensa.

La implantación en Granada de los pliegos informativos o históricos fue importante. Aun a falta de catálogos exhaustivos, en nuestra memoria de licenciatura (10), analizamos y catalogamos 150 impresos, lo que nos permite estimar que la situación de Granada, entre el resto de las grandes ciudades, debió de ser similar a la de los pliegos poéticos, aunque quizás con una mayor preponderancia de Sevilla.

Los pliegos históricos o relaciones han sido poco estudiados. Aparte de las referencias existentes en obras generales, hemos de señalar el catálogo de Agulló y Cobo (11), así como una obra antigua referente sólo a las granadinas y que aún conserva parte de su valor: las Relaciones del siglo XVII, de Palanco Romero, en donde se incluyen trece impresos encontrados en la Biblioteca Universitaria de Granada.

7 “Es opinió generalitzada entre els bibliografs que solament una petita part de la producció europea de plecs noticiers de l'época ha arribat a nosaltres. ." Blasco, Ricard: La prensa del País Valenciá, 17901983. Valencia, 1983, pág. 34.

8 Aguilar Piñal, M., Romancero popular del siglo XVIII. Madrid,1972, pág. XIII.

9 González Antón, Javier, Ob. Ct. pág. 75.

10 ídem. pp. 76 y ss,.

11 Agulló y Cobo: Relaciones de sucesos. I: Año 1477-1619. Madrid. CSIC. 1966. 
El estudio de la evolución de la información impresa se encuentra en el caso de Granada enmarcado en unas coordenadas muy peculiares. Los primeros antecendentes de la información en el moderno sentido del término, la información impresa, necesariamente han de arrancar del periodo final del siglo XV. Ahora bien, las peculiares características sociopolíticas del Reino de Granada, con su tardía incorporación al reino de Castilla, implican igualmente un corte determinante respecto a su inmediato pasado. De ahí que no existan prácticamente antecedentes directos de la información en Granada con anterioridad al año 1500 y que sus precedentes sólo lo sean de un modo tangencial, información con contenidos acerca del reino de Granada pero transmitida desde fuera de él, cronistas extraños al reino, al que se aproximan por los avatares bélicos, etc.

El punto de arranque de la información impresa granadina resulta, pues, por partida doble, mucho más diáfano: dominación cristiana e introducción de la imprenta, acontecimientos ambos de finales del XV.

El primero de los condicionantes para la edición de publicaciones granadinas era la existencia o no de imprentas capacitadas, hecho pronto superado con creces ya que Granada fue una de las capitales españolas con mayor número de talleres y de obras. Así, sólo en siete años, los que van desde 1566 a 1573, hay 25 pliegos poéticos impresos en el taller de Hugo de Mena, cantidad que Rodríguez Moñino (12) considera que no tuvo parangón por entonces en toda España.

Para el siglo XVII García de Enterría (13) señala a Granada como la sexta capital española en producción de pliegos sueltos poéticos, con 15 durante este periodo. Si a ello añadimos los citados por Caro Baroja (14), o Rodríguez Moñino y el abundante material que hemos encontrado, cabe considerar a Granada como una de las capitales con mayor número de pliegos impresos.

Ciñéndonos a los antecedentes más directos, vamos a apuntar brevemente las características de los impresos que hicieron posible la aparición de la prensa: las relaciones, junto con los romances, los más populares y difundidos entre los pliegos sueltos.

En conformidad con su presentación, Rodríguez Moñino (15) considera como Los pliegos sueltos a aquellos impresos de pocas páginas no encuadernables:

\section{Por pliego suelto entendemos, en general, un cuaderno de pocas hojas... aunque en principio sirvió como norma atenerse a lo que en verdad era un pliego, es decir,}

\footnotetext{
12 Rodríguez Moñino, Antonio, Diccionario de pliegos sueltos poéticos. Madrid, 1970.

13 García de Enterría, María Cruz, El pliego suelto poético en los siglos XVI y XVII de la literatura española. Madrid, 1978.

14 Caro Baroja, Julio, La literatura de cordel. Madrid, 1969.

15 Rodríguez Moñino, Antonio, Poesía y cancioneros (siglo XVI). Madrid, 1968, págs. 31 y ss.
} 
una hoja de papel en su tamaño normal, doblada dos veces para obtener ocho páginas, poco a poco se ha ido ensanchando el concepto..

Una primera distinción deslinda los pliegos sueltos de aquellos impresos también de pocas páginas de carácter religioso o judicial, que por tener un desarrollo particular no conducen al nacimiento de las publicaciones periódicas ni son de forma estricta medios de difusión informativa de actualidad. Entre ellos se encuentran los edictos, bandos, sermones, bulas, oraciones (16), memoriales (17), representaciones (18), sentencias (19), programas (20), etc.

De carácter informativo, pero de tema particular y edición ocasional y no repetible, ni periódica, serían los manifiestos (21) y no dependientes de periodicidad y ocasionales, los libelos (22) carteles o bandos. Ellos tienen un componente informativo, pero con un desarrollo paralelo y distinto al de la prensa, que en muchos casos los mantiene hoy en vigencia de forma independiente.

Entre los pliegos sueltos hemos de distinguir también los de contenido imaginativo, o literario, y los informativos o históricos. También Domínguez Ortiz señala estos dos grandes apartados: "Según que el contenido sea fabulatorio (coplas, romances, oraciones), o informativo: las relaciones", de diverso valor y tema, precedentes de la prensa. Será a los segundos a los que nos dediquemos ahora.

16 Naxera, Iván de, Fraile. Oración panegírica moral, en la festividad que celebró la Sociedad Regia de Médicos de Sevilla, el segundo día de Pascua de Pentecostés. Granada, Imp. de Nicolás Prieto, 1714. 6 hojas más 22 págs. (Sevilla, Real Academia de Medicina, 1/512 R-299).

17 Memorial de la ciudad de Granada al Rey Don Felipe III representándole los inconvenientes del uso de coches y suplicándole su abolición. (s.1., s.i., s.a.: 1615?) Madrid, Biblioteca Nacional, Gayangos 469/6.

18 Representación al rey por la Iglesia de Motril (s.1., s.1., s.a.) Madrid, Biblioteca Nacional, Gayangos, 481-3.

19 Innovación de las constitvciones y decretos que han salido en favor de la sentencia que afirma ser la Alma de la Bienaventurada Virgen Maria en su Creación, y Infusión en su Cuerpo preservada del pecado original, hecho por Nuestro Santo Padre Alexandro VII. En Granada, en la Imprenta Real por Francisco Sánchez, 1662. 2 folios. Madrid, Biblioteca Nacional, Gayangos, 469-103.

20 Programa de fiestas religiosas por la declaración de la Inmaculada Concepción de María Santísima. En Granada, por Baltasar de Bolibar, en la Calle de Abenamar, 1662. 1 fol. Madrid, Biblioteca Nacional, 469-102.

21 Manifiesto del Colegio de Abogados de Granada sobre las defensas en los tribunales eclesiásticos (5.1.: Granada?, s.i.) 1762. Madrid, Biblioteca Nacional, Gayangos, 481-14.

22 Discurso de D. Franco Guillen Bellaguila contra un sedicioso judio que en la noche del Jueves Santo de 1640 fixo un infame libelo en las casas del Cabildo de Granada, persuadiendo en él a la ciudad a que dexase la fé de J.C. y siguiese la de Moyses, vituperando asimismo la Virginidad y pureza de Maria SS. El parecer o discurso se dirige a probar no se le debe perdonar la vida, aún en el caso de arrepentirse. Citado por T. Navarrete: La biblioteca del Colegio de San Pablo de Granada. Granada, memoria de licenciatura. 


\section{Las relaciones}

Los pliegos sueltos históricos, informativos o relaciones tratan de acontecimientos reales y adolecen por tanto del carácter imaginativo inherente a sus similares literarios. Al basarse en la realidad, son excelentes instrumentos de información, así como eficaz sistema de propaganda política, características ambas que se dan igualmente en el posterior periodismo.

Fuensanta del Valle (23) resalta su carácter popular y gran difusión, favorecida por su escaso precio, y considera que es el origen exacto del periódico ya que se encuentra en la necesidad de reunir en un pequeño espacio, en una misma hoja impresa, o en 3 ó 4 a lo sumo, muchas noticias e informaciones de todas clases.

$\mathrm{Su}$ origen popular explica también que la impresión no fuera cuidada, con abundantes erratas tipográficas y linguiísticas, con una sintaxis y ortografía muy deficientes. Escritas en prosa, podían ser enumeración de datos o narraciones más cuidadas, casi siempre en tono laudatorio con exageración de los aspectos favorables.

\section{La presentación}

Las primeras publicaciones informativas son las Relaciones históricas, y la mayoría de las 150 que he podido encontrar tienen un formato de folio, 28 x 20 centímetros, con dos hojas, aunque más esporádicamente aparecen también en tamaño de $4^{\circ}, 20$ × 14 y 8 páginas, formato que es precisamente el adoptado por las gacetas. Como nos señala Bellanger (24), el material de impresión de las gacetas era el mismo en todo el mundo, el de la impresión clásica: caracteres móviles, prensa o prensas manuales, y la tinta y papel corrientemente empleados.

El formato de las relaciones era ciertamente pequeño, aunque no uniforme; la cantidad del texto era seguramente la causa de los distintos formatos, ya que se elegía el folio o en octava según la extensión de lo narrado. También los periódicos del primer momento solían no pasar de las cuatro páginas, y sólo cuando tenían noticias de mayor importancia aumentaban el número de páginas.

Las relaciones normalmente estaban confeccionadas en un pliego doblado en cuatro páginas, no difiriendo grandemente de los pliegos poéticos, normalmente también un pliego suelto doblado una o dos veces, con 4 u 8 páginas en $4^{\circ}$ u $8^{\circ}$, a una o dos columnas, y con tipos de letras normal, negrita o cursiva.

Los grabados son frecuentes en las relaciones, aunque la mayoría de las veces no guardan una estrecha relación con el texto que ilustra, ya que el editor

23 Fuensanta del Valle. La Historia del periodismo político. Discurso de recepción ante la Real Academia de Ciencias morales y políticas. Madrid, 1892.

24 Bellanger, Ob. cit., pág. 11. 
suele aprovechar los utilizados en los libros que editaba, siempre que tengan temas semejantes; así, se repiten frecuentemente las figuras de barcas cuando el asunto hacía referencia a confrontaciones navales.

Los tipos de letra utilizados corrientemente son los góticos, el romano y el itálico,. Como nos informa Bellanger (25), cada fundador trabaja por su propia iniciativa, y en el XVIII cada cuerpo de tipo tiene una designación particular en función del que lo usa; así, el cuerpo 7 se denomina Mignonne, el 8 Gaillarde, el 9 Petit Romain. Sólo a finales del siglo, en 1775, Didot sustituye la antigua denominación por cifras relacionadas con el sistema métrico.

Los cuerpos de letra suelen ser pequeños. Utilizando como medida el actual punto Didot, son de una gama de tamaños que varía entre los 8 y 12 puntos, para el texto; los más pequeños, para algunas relaciones y las gacetas normalmente; y los tamaños alrededor del 12 para las relaciones y pronósticos.

Los titulares en las relaciones solían encabezar el texto en los primeros tiempos, colocados en la parte superior de la página; posteriormente, alternan con los que ocupan toda la primera página a modo de portada.

Analizadas globalmente, las relaciones guardan siempre una gran semejanza, tanto en su número de páginas como en columnas, formato, tipos, cuerpos de letra y grabados.

Durante todo este periodo fue, pues, muy arcaica la presentación, faltando por completo el moderno instinto periodístico de presentar un reclamo atrayente al público. Lo importante era el contenido expresado y no su presentación. Las portadas iguales, los tipos uniformes, los tamaños escasos, etc., buscan asemejarse a un fascículo y no a un periódico. Todo ello hace que los arcaísmos sean manifiestos, y la visualización deficiente, por lo que ciertamente la cultura visual aún no se vaticina ante el predominio absoluto de lo escrito.

La impresión se seguía haciendo en la «prensa plana» inventada por Gutenberg, a la que apenas se le habían introducido novedades. La prensa era de madera, una máquina horizontal de presión y con superficies planas, y el mecanismo se limitaba a hacer descender la platina hasta apretarse sobre la forma y levantarse posteriormente (26). Los caracteres móviles en la composición y la prensa de Gutenberg son los utilizados en relaciones y gaceta, es la culminación de la prensa plana, y de la fuerza del hombre como motriz: "correspond non seulement au rigne de la typographie, mais a celui de la presse plate, utilisant la pression d'un plateau sur une forme plate. La force motrice est fournie par I'homme s'aidant d'un levier... "(27)

25 ídem, pág. 11 y ss. .

26 Millares Carlo, Agustín, Introducción a la historia del libro y las bibliotecas. México, 1975, p-ags. 190 y ss.

27 Bellanger, Ob. cit., pág. 5. 
De cualquier forma hay una cierta evolución, En España, a lo largo del siglo XVII se produce una manifiesta decadencia de la tipografía, pese a la existencia de impresores de calidad y de textos literarios y religiosos para componer. Ello se debió a la débil situación económica, que llevó al uso de papel de ínfima calidad, tipos muy usados y a la falta de competitividad (28). Por contra, a lo largo del siglo de la Ilustración se produce un resurgir de la tipografía española, fundamentalmente a partir de Carlos III, muy aficionado a la impresión.

Hasta principios del siglo XIX sólo se habían conseguido aportar ligeras innovaciones a la prensa de Gutemberg, como el tornillo de hierro o el empleo de la franqueta; aunque básicamente, el principio de la prensa tipográfica no cambiara hasta la invención de la prensa de cilindro. Faltaban, por tanto, casi todos los progresos fundamentales. La composición fue igualmente artesanal hasta finales del siglo XIX, haciéndose a mano a base de reunir tipos sueltos.

Su aceptación y el interés que se muestra por estos impresos era muy grande, hasta el punto de ser frecuente la reedición de la información en distintas ciudades para darlas a conocer a sus ciudadanos, cuando además el tamaño de las tiradas y el efecto geográfico era muy limitado. De ello tenemos múltiples ejemplos, caso de las dos relaciones impresas en Sevilla y Granada en 1621 Copia segunda. Maravilloso insigne y costoso arco, o Puerta, que los Ingleses han hecho en el Pilouriño viejo, por donde ha de entrar su Magestad en Lisboa. Impresso con licencia en Seuilla por Iuan Serrano, y por su original en Granada por Francisco Heylan, Impresor de la Real Chancillería, en la calle del Agua. (29)

Otro caso afecta a Canarias, la que en 1630 describe la victoria de don Fadrique de Toledo sobre cuarenta naves holandesas, también alcanzan gran difusión y se imprimen en más de dos ciudades casi simultáneamente, en este caso en Valladolid y Granada.

Aunque la mayoría son monotemáticas, en algunos casos se asemejan a los periódicos en cuanto que incluyen en una relación más de una noticia de actualidad; es el caso de la que el año 1631 trata de temas tan dispares como la alegría por la llegada de la flota de América, con la catástrofe de un incendio en la Plaza Mayor de Madrid, Relacion del lastimoso incendio que en Domingo seis de Julio deste año de 1631. emprendió a las dos de la mañana en la Real Plaça de Madrid...sucessos notables, perdida de hazienda y vidas, medios que se ha tornado para reparar los daños del fuego y las alegres nueuas de las pazes de Italia, y llegada de nuestra armada de Pernambuco. Impresso con licencia en Granada,

28 Ruiz Lasala, Inocencio, Influencia del papel en la vida del hombre, en Ensayos bio-bibliográficos. Zaragoza, 1983.

292 folios a 1 y 2 cols. Granada, Biblioteca Universitaria, A-31, 123 
en la Imprenta de Martin Fernández Zambrano, en la calle de los Gomeles, año de 1631. (30)

\section{Los autores y los impresores}

Entre los autores cabe señalar a Blas Fernández de Santistevan (31), coetáneo de Henríquez de Jorquera. En 1624, Diego Ruiz, que escribe en Madrid publicaciones que se imprimen en su ciudad natal (32); Cristóval Bravo, cordobés, ciego y autor también de populares pliegos literarios, como el Testamento del Gallo (33); o Francisco del Tello, en 1598. También, Bernardo del Toro en 1615; Tomás Ybio Calderón, tres años después, o Pedro Ruiz de Céspedes, en 1620.

En la difusión de la información juega un papel fundamental la existencia de imprentas. Sólo cuatro años después de consumada la conquista del reino por los cristianos, en 1496, se instalan en la ciudad los primeros impresores, auspiciados por el obispo Hernando de Talavera. Se trataba de Meynardo Hungut y Johannes de Mirenberga, a los que sigue el primer español, el salmantino Juan de Varela (34). La mayoría de los impresores granadinos estuvieron ligados directamente a la difusión informativa, primero con las relaciones y luego con las gacetas y periódicos. Entre ellos se encuentran verdaderos artistas, caso de Francisco Heylan, de la dinastía de su nombre, nacido en Amberes en 1584 y muerto en Granada en 1650. Fue éste un magnífico grabador, burilista y tipógrafo, y entre sus cargos ostentó el de impresor de la Real Chancillería de Granada; destacó como reproductor de retratos y de portadas hasta el punto de que sus planchas seguían siendo aprovechadas en ediciones más de un siglo posteriores (35).

También son frecuentes las empresas familiares de impresores como los Mena, dirigida en 1552 por Sebastián y de 1566 al 73 por Hugo. Los Muñoz, Sebastián en 1610 y Juan desde 1616 al 24; ó Pedro Bolívar en 1620 y Baltasar, desde 1658 hasta 1668 .

Otros destacan por ser prolíficos artesanos, hasta el punto de que la gran cantidad de pliegos sueltos que editan en corto espacio de tiempo hace que posean un cierto sello de periodicidad, así Bartolomé de Lorenzana publica 16 relaciones

302 folios. Granada, Biblioteca Universitaria, Col, Montenegro, S.A,E-31, t-143, No 3.

31 También es autor de pliegos poéticos, como el poema Fiestas reales en Granada, con motivo del nacimiento del Príncipe Baltasar Carlos. Granada, Imp. de Martín Fernández Zambrano, 1630, 8 folios en $4^{\circ}$.

32 Relación que embió Diego Ruyz, teniente de Maestre de Campo General y natural de la ciudad de Granada, y traslado de la carta

33 Obra muy graciosa para reir, y passar el tiempo la cual se llama el testamento del Gallo.., compuesta por Cristóval Bravo, privado de vista y natural de Córdoba.

34 Gómez Moreno, Los primeros impresores granadinos, en Revista de Archivos, Bibliotecas y Museos, 3 ? época, tomo 40 (1900), 463-483.

35 Moreno Garrido, Antonio, El grabado en Granada durante el siglo XVII. 1, La Calcografía. Granada, 1986. 
históricas desde 1618 al 31; Martín Fernández Zambrano, publicó 7 entre los años de 1612 y 1630; Juan Muñoz, 6 entre 1616 y 1624. Francisco Heylan, que editó igualmente 6 entre los años 1620 y 1625; o Sebastián de Mena, que imprimió 5 en los últimos años del siglo XVI. También para los pliegos poéticos encontramos prolíficos impresores, como Hugo de Mena, con 25 en sólo siete años.

\section{Las fuentes de la información}

Por lo que atañe a las fuentes de la información, Timoteo Álvarez (36) señala que la superficie redaccional, los textos, se pueden clasificar en las secciones normales de nacional, internacional, regional y local, sin que tengan en esa época que aparecer como secciones fijas, sino más bien a las que sólo se refieren cuando algún asunto importante lo exige. Siendo para el siglo XVIII y XIX las secciones ya más diferenciadas e importantes, las de internacional y nacional.

La información internacional aparece por primera vez en los pliegos sueltos, entre las relaciones. La primera, titulada Relación de la admirable toma de la ciudad de Amiens en el 11 de Março de 1597 años, pudo ser obra de Agustín Morales y fue impresa en Granada por Sebastián de Mena. Otra del mismo año se titula Nueva relación de las grandes victorias que ha tenido el emperador contra el gran turco... también ay auisos de Francia y otras partes, perteneciendo al mismo impresor que la anterior.

Entre las conservadas, las más antiguas datan de mediados del siglo XVI, es el caso en 1563 de la Relación muy verdadera de todo lo que ha pasado en la venida y cerco que el rey de Argel puso sobre Orán. Granada, René Rabut, 1563. (37)

La información de carácter nacional más antigua entre las relaciones conservadas data de 1612 y se titula Relación de un sacerdote que murió en Valencia, año 1612, el cual ha hecho Ntro. Señor por él doscientos sesenta milagros... llamábase Francisco Jerónimo Simó. (38)

La información regional aparece por primera vez en una relación fechada en 1611 que trata de un enfrentamiento naval con turcos y holandeses en aguas de Málaga: Relación verdadera del suceso que tuvo don Pedro de Toledo, Marqués de Villafranca, junto a la ciudad de Málaga con dos navíos turcos y Olandeses piratas y como los rindió..

36 Alvarez, Jesús Timoteo, Restauración y prensa de masas... pág..329.

37 En $4^{\circ} .20 \mathrm{ctms}$. Palau tomo VI, pág. 237. $\mathrm{n}^{\circ}$ 257.181. Rodríguez Joulia, 85.

38 Las noticias sobre Andalucía en el extranjero son la contrapartida. Así, Gilles Feyell (La presse provinciale au XVIIIe siécle,Grenoble, 1983, pág. 60) señala que el Bulletin de Narbonne en 1780 incluía "Cartas políticas" provenientes de Cádiz. 
El primer pliego que aporta información sobre Granada, y posiblemente el primer pliego poético español, como indica Julio Caro Baroja (39), es el mencionado por Fernando Colón: Conquista del Reino de Granada, opúsculo en coplas, impreso probablemente en 1482, como señalan sus primeros versos: Año de ochenta y dos / el poder vino mostrando ... Otro pliego del momento, que incluye información local, es el In lauden.. .serenissimi Ferdinandi Hispaniarum, impreso en Roma y luego en París con el título de La tres célebre digne de memoire et victorieuse prise de la cité de Grenade... papeles que muy probablemente fueron impresos posteriormente en Granada. Ya con certeza impresas en la ciudad fueron las Observaciones diarias de acontecimientos granadinos desde el 4 de Agosto de 1552, debidas probablemente al taller de Sebastián de Mena.

\section{Los contenidos}

Versan casi siempre sobre la actualidad del mediterráneo o América en los siglos XVI y XVII, para desplazarse posteriormente el interés al atlántico norte, Marruecos y las guerras españolas de Cataluña, Portugal y de sucesión.

Concomitancias periodísticas se encuentran también, en el estilo tremendista casi constante de las relaciones históricas de sucesos, no sólo por la truculencia con la que narran los hechos, sino igualmente por el tono moralista que suele acompañar a la descripción.

Respecto a la dudosa verosimilitud de la información, del carácter objetivo o no de las relaciones, se constata que cuando abandonan el relato directo de la realidad suelen acentuar la tergiversación acomodándola muchas veces a intereses determinados, tal hecho aunque les resta valor como dato histórico no hace sino inscribirlos aún más en la línea informativa que conduce a la prensa, baste recordar que durante la ilustración era popular el dicho de "mentir más que la gaceta". El que aquellos precursores lo hicieran en un mayor o menor grado dependió únicamente de la progresiva perfección de las técnicas de enmascaramiento, y no restan en las relaciones valor informativo alguno.

También, a semejanza de las posteriores, muchas relaciones recogen la información de otros impresos hasta el punto de editar nuevamente las relaciones impresas con anterioridad en otra localidad. Ello va ligado casi siempre a la importancia de la noticia y al grado de actualidad que posea.

Las cuestiones abordadas son diversas y responden en general al interés de la sociedad del momento. Las noticias de carácter político no suelen ser profundas y casi todas poseen unas mismas características, como el muy arraigado sentimiento monárquico; con frecuentes reseñas de acontecimientos reales, caso de la de 1623 describe la llegada: Relación de la entrada que el Píincipe de Gales sucessor 
del Reyno de Inglaterra hizo en Madrid domingo veynte y seys de Março, de mil seyscientos y veynte y tres, y de las prevenciones que para ello se hizieron. Con licencia, Impressa en Granada, por Bartolomé de Lorençana y Vreña, en la calle del Pan, Año de 1623. (40)

De fiestas, reales, eclesiásticas, etc. hay muchos ejemplos entre los que cabe entresacar la de 1668: Relación breve de las Fiestas que el Real Convento de Santa Cruz de Granada dispuso y hizo en la Beatificación de la Venerable, y Esclarecida Virgen la Bienaventurada Rosa de St ${ }^{\circ}$ Maria De la Tercera Orden de Nuestro Glorioso Padre y Patriaca St Domingo de Guzman, natural de la Ciudad de Lima, y Cabeça de el Imperio de el Perú \& c.. Al fin: Con licencia impresa en Granada, Por Baltasar de Bolíbar, impresor del S. Oficio de la Inquisición, en la calle de Abenamar. Año de 1668. (41)

La mayoría tienen como tema acciones bélicas, así la del ciego Gaspar de la Cintera en el año 1572; Aquí se contienen dos admirables victorias que Dios nuestro señor ha dado a los fieles contra los endiablados Turcos... La primera la conquista de la hermosa Velona. La otra el fortíssimo Castilnouo fuercas muy poderosas e importantes con otras muchas y muy marauillosas cosas que en fauor de la sancta liga han acontecido. Contado todo... por Gaspar de la Cintera, priuado de la vista, natural de Ubeda y vezino de la cludad de Granada. Granada, Hugo de Mena, 1572. (42)

También pueden seguirse a lo largo de las distintas relaciones los diversos disturbios y guerras civiles: así, en 1652 una relación se hace eco del perdón a la ciudad de Barcelona: Perdón general que el Señor Don luan de Avstria hizo en nombre de su Magestad (Dios le guarde) a la Ciudad de Barcelona, auiendose rendido, y puesto en sus Reales pies, como plenipotenciario de las Armas Reales de su Magestad, en once de Octubre de 1652. (43)

O ya en 1706, coetánea con las primeras gacetas periódicas, de la lucha entre el candidato borbónico y el austríaco: Copia de Carta que escrive el Rey Nuestro Señor (Dios le guarde) desde su Campo Real de Jadraque. Con fecha de 7 de Julio de este presente año de 1706 Al Señor Presidente de esta Real Chancillería, Y otra escrita à dicho Señor Presidente por el Señor D. Joseph Grimaldo, secretario del Despacho Vniversal, por lo tocante a la guerra, su fecha de 8 de este mes, que una, y otra, se han recibido oy 19 de Julio. Impresso en Granada, en la Imprenta Real de Francisco de Ochoa, impresor del Santo Oficio. A costa de Nicolas Prieto, mercader de libros, y se vende en su casa. (44)

\footnotetext{
402 folios. Granada, Biblioteca Universitaria, Col. Montenegro, S-AE-31, t-123, $\mathrm{n}^{\mathrm{o}} 56$

41 Granada, Biblioteca Universitaria, Col. Montenegro, s- a, E-31, t-128, no 63.

422 h. 20 ctms. Escudo real en la portada. Bauer, Relaciones V. págs. 19-35. Gallardo, II,nº 1821. Durán ILXIX.

432 hojas. 20 ctms. Madrid, Biblioteca Nacional, R Varios 4- 22. Uriarte, anónimos II, $n^{\circ} 1911$.

442 hojas en $4^{\circ}, 1$ grabado Granada, BU, Col. Montenegro, S-A, E-31, 259 (6)
} 
Las de tipo social, pese a ser escasas, son del mayor interés. Las que menos, versan sobre fiestas y otros divertimentos, éstas responden a diversas motivaciones pero cuentan siempre con el masivo reconocimiento del pueblo, ávido de diversión. Ya hemos señalado las suscitadas por acontecimientos reales: bodas, nacimientos, etc., ó religioso: beatificaciones, conmemoraciones del Santísimo Sacramento, y demás, en casi todas ellas el estilo informativo es muy descriptivo, dando noticia varia y rica del pintoresquismo del ceremonial, engalanamiento y actos llevados a cabo, etc. En otros casos, los motivos son puramente económicos, como se manifiesta en el júbilo por la vital flota que de América aportaba recursos a la deficitaria situación económica de la monarquía española: Blas Fernández de Santistevan describe con pintoresquismo la correspondiente al año 1630: Relación verdadera y cierta de la desseada y felice venida de la flota de Nuena España, y galeones de tierra firme, y de la Armada Real del Mar Océano. Dase quenta de las mercaderias plata, oro, y perlas que truxo registrada y el valor dellas este año de 1630. Reynando Don Felípe III nuestro Señor. Recopilada por Blas Fernández de Santistevan, vezino desta ciudad. En Granada, En la imprenta de Martín Fernández, frontero de San Gil. Año de 1630. (45)

Aunque en la realidad en la mayoría de los casos las novedades suelen ser negativas, las relaciones que describen catástrofes naturales o provocadas por el hombre, aunque también se imprimen, son minoría frente a las que se hacen eco de alegrías, pese a ello también las hay de todo tipo: tempestades, inundaciones, terremotos, epidemias.

Ciertamente, los sucesos son materia ávida para incultos lectores y las relaciones tratan frecuentemente de calamidades públicas o desgraciados avatares personales. Entre éstas últimas pueden señalarse las de muertes de reyes o enemigos, y, de las primeras, los diversos terremotos, como en 1614 la que describe la Veryssyma y notable relación en la qual se declara el es/pantoso temblor ,y tempestad, que sucedió en la ciu/dad de Granada, a cinco del mes de Octubre deste pre/sente año, hase declarado las desgracias que sucedie/ron, y como tembló la tierra en once dias tres vezes,/ Es obra digna de ser leyda. Lleva al cauo vn Roman/ce nuevo muy curioso, sobre la temática de las /mugeres, y varias siguidillas nиеиаs de la com/petencia que tuиo el paje Vacallan/con su amo./Impreso con licencia en Granada, en casa de Bartolomé de Lorenzana, año de 1614. (46)

Otros desastres naturales, como las tempestades e inundaciones, unas veces se encuentran juntas como consecuencia una de otra, y otras por separado, entre las primeras, la acaecida en Granada el año 1629, Relación de la tempestad, y diluio que sobreuíno este año de mil y seyscíentos y veynte y nueue a veynte y

452 folios. Granada, Biblioteca Universitaria, Col.Montenegro, S-A, E-3I, T-143, no 7.

464 hojas en $4^{\circ}$. un grabado. Londres, British Museum, 1072 g 26 (21). Citada por M. Cruz García de Enterría. 
ocho del mes de Agosto día del señor San Agustín en la Ciudad de Granada. donde se da Cuenta de la gente que peligró y Casas que se anegaron. Con licencía , Impresso en Granada por Francíso Heylan, de la Real Chancíllería, en la Calle del Agua, año de mil y seyscíentos y veynte nueue (47). Tres años antes, en 1626, Juan Serrano de Vargas, relata igualmente las inundaciones que afectan a casi todos los reinos: Relación general de todos los daños que han hecho los Ríos, ayres y tormentas en Salamanca, Zamora, Toledo, Almagro, Cordoua, Ecija, Seuilla, Merida, Medellín, Badajoz, Murcia, Valladolid, Medina del Campo, y otras villas y lugares de Castilla, y Andaluzia, y en los caminos, y campos. Recopilada de cartas embiadas de las dichas ciudades, por Iuan Serrano de Vargas y Vreña. natural de Salamanca. Impresso con licencia en Granada, por Bartolomé dc Lorençana. Año de 1626 (48)

En otros casos, las catástrofes pueden ser debidas, real o atribuidamente, a la mano del hombre, ya sean incendios, epidemias, etc. En muchos casos imputados a determinados colectivos. Entre las primeras cabe distinguir, en 1677, la Verdadera relación del formidable incendio de la Yglesia, y convento de Religiosas de N.S. de la Concepción de la Civdad de Gvadix el día Qvatro de Ivlio de 1677. Con licencia Impressa en Granada en la Imprenta Real de Francisco de Ochoa. (49)

Si en el caso anterior la fuente de información es puramente local, en otros como las epidemias pueden llegar, en 1630, de lugares tan alejados como Italia, Relación verdadera de lo que aora nuenamente ha sucedido en la ciudad de Milán. Dase quenta del exemplar castigo y justicia que hizieron los senadores de Milan en dos hombres naturales de la dicha ciudad, por auer derramado poluos, ponçoñosos y apestados. $Y$ assimismo se declara el número de gente que hasta aora ha muerto y de otras cosas muy notables dignas de saberse. Impressa con licencia en Granada, en casa de Bartolomé de Lorençana, en la calle del Pan , año de 1630. (50)

Encontramos también impresos que hacen referencia a situaciones de intolerancia social, y heterodoxos, con descripción de supuestos casos de hechicería, brujas, etc. En poblaciones tán próximas como Priego: Relación verisima en la qual selda cuerta de las muchas hechicerías y brujas que agora se han des/ cubierto en la villa de Priego, por una maestra desta endiablada/ciencia que en la dicha villa estaba muchos años avía: Dase cuen/ta de muchas muertes y casos feos que causó esta y otras sus com/pañeras que ella va nombrando, las quales van prendien/do por toda la tierra con muy gran cuidado./ Todo ello visto y

\footnotetext{
472 folios. 1 grabado. Madrid-BN, Varios 180/49. Gallardo I- 862. Vindel: Catálogo de libros raros, 793. 482 fol, a 1 col. Granada, Biblioteca Universitaria, Col. Montenegro, S-A, E-31, T-143, no 29.

494 folios,. 1 grabado. Granada- BU. Col. Montenegro; S-A, E-31 t-138, n ${ }^{\circ}-72$

502 folios. Granada, Biblioteca Universitaria, Col. Montenegro, S-A, E 31.
} 
examinado al pie de la letra, por un testigo de vista que presente se halló a los tormentos y confessiones de/llas. Impresso con licencia en Granada en casa de Martín Fernández, en la calle de Ossorio, año de mily seis cientos y quince. (51)

Las relaciones también son buen reflejo de situaciones sociales, y en algunos casos de desórdenes públicos, y hasta de difusión de información contraria a la monarquía y a la religión católica, así hay de diversos autos de fe, como el de 1624: Relacion verdadera del Avto de la Fé que se celebr6 en la villa de Madrid a catorze días del mes de Iulio deste presente año de 1624. Dase cuenta de la justicia que se hizo de un Herege Apostata natural de la ciudad de Angers en el Reyno de Francia llamado Reynados de Peralta, y las confesiones que hizo ante el Tribunal. de la Santa Inquisición. Assi mismo se trata de la solemne processión que su Magestad mandó se hiziesse en el. Convento de San Felipe de la Orden de $S$, Agustin, a honor del Santisimo Sacramento, a la qual assistieron todos los grandes de la Corte. Con Licencia. En Granada, por Bartolomé de Lorençana y Ureña, Año de 1624. (52)

Cuestiones pintorescas, y que atraen grandemente la atención de los lectores, es la presencia real o supuesta de mostruos, animales extraordinarios "capaces de actuar inteligentemente", es la que nos describe en 1612 Juan de Fonseca: Notable y prodigiosa Relación / que truxo el pradre Geronymo Xauier de la Compañia de IESVS/ en que se da cuenta de un animal, o monstruo, que está en la Prouin/ cia de Vengala, que penetra todo lo passado, y futuro, en tal grado q/ parece persona racional, y no le falta mas de hablar y entiende quanto le dán por escrito; y si se le dan el nombre de IESUS lo reuerencial y aborrece los nombres de los ídolos falsos: cerca desto se han hecho/ grandes experiencias, y tales ,que ha sido causa que el Rey de Mogis se ha convertido a le Santa Fé Catolica... compuesto por el licenciado luan de Fonseca, natural de Logroño. Con licencia imprressol en Granada, en casa de Bartolomé de Lorenzana. Año de 1612. (53). Tal situación extraordinaria, en muchos casos se liga a la intervención sobrenatural de los poderes religiosos, milagros y curaciones que tienen también gran éxito y predicamento entre los incautos lectores: Relacion breve de un milagro que Nuestro Señor ha obrado por intercessión de la Gloriosa Santa Madre Teresa de Iesus, fundadora de los decalsos Carmelitas, resucitando una niña, y de la auerigación, que en contraditorio juycio se hizo en Guadix, en comprouacion del ordenada por Don Diego Santa Cruz Saavedra, Chantre de la Santa Yglesia desta ciudad de Guadix. Granada, Martín Fernández Zambrano. (54)

514 hojas en $4^{\circ}$. Gallardo. Biblioteca de libros raros y curiosos.

522 fol., a 1 col. 1 grabado. Granada, Biblioteca Universitaria, Col. Montenegro, S-A, E-31, n 73.

533 (4) hojas. $4^{\circ}$. Londres, British Museum,1072 g 26 (10).

547 fol. en $4^{\circ}$. Madrid, Biblioteca Nacional V-56-29. 
También de cuestiones locales, aunque de otra índole, en este caso de cuestiones más políticas de oposición al régimen absoluto y a la iglesia católica, y que provocó la inmediata respuesta de los informadores oficiales con relaciones y discursos impresos, es la de Gabriel Rodríguez de Escaviá, el año 1640, sobre la circulación de papeles clandestinos en la ciudad: Exortación al herege que puso en la Ciudad de Granada, lueves Santo, en la noche cinco de Abril del año de mil y seiscientos y quarenta, un papel contra nuestra Santa Fe Católica. Por Gabriel Rodríguez de Escaviá. Granada, Inprenta Real Francisco Garcia de Velasco.1640. (55)

Pero lo que culmina en 1808 en el primer diario tiene sus orígenes en algunas de las primitivas publicaciones informativas, como aquellas relaciones históricas que, pese a su carácter independiente tratan reiteradamente acerca de un mismo asunto, aportando matizaciones que va proporcionando la actualidad. Es el caso del impreso por Juan Muñoz en 1623 titulado Relaciones enviadas por el Duque de Pastrana en 26 y 28 de Abril de 1623. De los sucesos que a tenido en la presa de los báxeles redondos de turcos, en viaxe de Roma...(56) donde en una sola impresión incluye dos relaciones próximas en fecha y sobre un mismo tema, con lo que de forma embrionaria aparece un cierto ritmo periódico.

Pronto tomará el relevo otra formulación arcaica de periodicidad, la que proporcionan los "almanaques" o "calendarios" y "pronósticos" o "piscator", impresos que, al marcarse unos límites en el tiempo de seis o doce meses, introducen una característica de ritmo más definida.

(Recibido el 12-2-2001, aceptado el 25-2-2001)

552 hojas. 30 ctms. Madrid, Biblioteca Nacional, Varios Especiales 177-30, 185-30.

56 Relaciones enviadas por el Duque de. Pastrana desde el puerto de Cadaqués en 26 y 28 de Abril de 1623 de los sucesos que a tenido en la presa de los baxeles redondos de turcos en el viaxe de Roma. Granada, Imp. de Juan Muñoz, 1623. 2 fol. a 1. col. 1 grabado. Granada, Biblioteca Universitaria, Col. Montenegro, 50 . 